http://jmscr.igmpublication.org/home/ ISSN (e)-2347-176x ISSN (p) 2455-0450 crossref DOI: https://dx.doi.org/10.18535/jmscr/v10i2.08

\title{
To Assess the Knowledge of Breast Self Examination and Awareness about Breast Cancer among the Female Students of Baba Farid Institute of Technology, Dehradun
}

Authors

\author{
Bisma Amin ${ }^{1}$, Nakul Kumar ${ }^{2}$, Shivam Kumar Mishra ${ }^{3}$, Moin Ahmed Chaudhary ${ }^{4}$, \\ Sujal Thakur ${ }^{5}$, Jagmeet Kour ${ }^{6}$, Pratibha Kumari ${ }^{7}$, Ramakanti Rajput ${ }^{8}$ \\ ${ }^{1}$ Assisstant Professor in Department of Radiology and Imaging Technology, Baba Farid Institute of \\ Technology, Dehradun \\ 2,3,4,5,6,7 Department of Radiology and Imaging Technology, Baba Farid Institute of Technology, Dehradun \\ ${ }^{8}$ Department of Microbiology, Baba Farid Institute of Technology, Dehradun
}

\begin{abstract}
Breast cancer is the most common invasive cancer in females. It is also a leading cause of cancer deaths among females. In rare instances, breast cancer can also affect males. This research will focus on breast cancer awareness in females and knowledge about BSE (BREAST SELF EXAMINATION)

Aim: To assess the knowledge of breast self examination and awareness about breast cancer among female students of BABA FARID INSTITUTE OF TECHNOLOGY

Method: An online survey was conducted among 600 female students of BABA FARID INSTITUTE OF TECHNOLOGY, DEHRADUN via email and personalized links. The survey consists of self structured questionnaire. Data was collected from participants

The study was conducted online among 400 female students of BABA FARID INSTITUTE OF TECHNOLOGY. A self structured questionnaire was prepared and validated. Data was collected from the participants by using convenience sampling technique and subjected to statistical analysis.

Result: Medical students have the highest knowledge about breast cancer and BSE (BREAST SELF EXAMINATION). 18-21 age groups were found to have great knowledge about breast cancer. 20 participants don't think screening is helpful in early detection of breast cancer. Media was found the common source of information about breast cancer. 46 (36.25) students were taught by their friends to perform BSE. 88 (69.3\%) participants don't practice BSE.

Conclusion: More awareness strategies need to be applied in order to raise the knowledge about BSE, mammography knowledge, and other preventive practice among young female population in this region. Along with this, there should be general health education programs directed towards achieving the needs to be launched immediately

Keywords: Breast cancer; Breast self examination; college students; female, knowledge; awareness.
\end{abstract}

\section{Introduction}

Breast cancer is the common type of cancer among females and in India more than one million cases are found per year. Breast cancer is a type of cancer that starts in the breast. Cancer starts when cells begin to grow out of control. Breast cancer cells usually form a tumor that can often be seen on an X-ray or felt as a lump. Breast cancer occurs almost entirely in women, but men can get breast cancer, too. ${ }^{1}$ Breast cancer is the second most common cancer in women after skin cancer. ${ }^{2}$ 


\section{Symptoms}

The first symptom of breast cancer is usually an area of thickened tissue in the breast or a lump in the breast or an armpit.

Other symptoms include Trusted Source:

- armpit or breast pain does not change with the monthly cycle

- pitting, like the surface of an orange, or color changes such as redness in the skin of the breast

- a rash around or on one nipple

- discharge from a nipple, which may contain blood

- a sunken or inverted nipple

- a change in the size or shape of the breast

- peeling, flaking, or scaling of the skin of the breast or nipple

Most breast lumps are not cancerous. However, anyone who notices a breast lump should have it checked by a healthcare professional. ${ }^{3}$ Breast screening is widely recommended as women are at risk of breast cancer. There is number of risk factors associated with increased risk of breast cancer such as age, family history, menopausal status and hormone replacement therapy (HRT). ${ }^{4}$

Breast cancer is distinguished from other types of cancer by the fact that it occurs in a visible organ and be detected and treated at an early stage. ${ }^{5}$

When breast cancer is detected early, the chances for survival are much better.

BSE

A breast self-exam is a step-by-step method women can use to examine their breasts. By looking at and feeling your breasts regularly, you can notice anything that seems abnormal. Monthly breast self-exams can help you detect changes that may be signs of infection or breast cancer (such as breast lumps or spots that feel different). Selfexams are important for breast health. But they should not replace exams and screening tests (such as mammograms) recommended by doctors. You should still see your primary care provider and/or gynecologist regularly. Women should do a breast self-exam once a month, every month. Women who are still menstruating (having a regular period) should perform a breast selfexam after their period. Women who have stopped menstruating and those who have very irregular periods can pick a day each month. ${ }^{6}$

Recommended preventive techniques to reduce breast cancer mortality and morbidity include breast self-examination (BSE), clinical breast examination (CBE), and mammography. ${ }^{7}$

Breast cancer is the most commonly occurring cancer in female gender everywhere around the world with an approximated 1.67million novel cases of cancer diagnosed in 2012 and around $5,70,000$ deaths in 2015. The incidence of LABC was $4.6 \%$ of all female breast cancer with annual incidence estimated to be around 1, 44000 of all new cases. ${ }^{8}$ It is the most commonly arising cancer amongst women in urban cities like Delhi, Mumbai, Kolkata, Ahmadabad and Trivandrum where it accounts for more than $30 \%$ of cancer cases in women as per ICMR cancer registry data. In rural areas of India, breast cancer is 2 nd prime cause of cancer only after cervical cancer. In Asian countries of the world, breast cancer incidence is highest in women with 40 years of age whereas in western countries like USA and Europe it is common in 60 years of age. 50\% cases of breast cancer in India are of premenopausal status. ${ }^{9}$ In congruence with Globocan 2012, India together with China and USA jointly constitutes for $1 / 3^{\text {rd }}$ of the breast cancer burden all-over the world. India currently is in a struggling position due to increased incidence $(11.54 \%)$ and increased death rate $(13.82 \%)$ due to breast carcinoma. The increase in incidence of breast cancer is probably higher among urban cities than in rural villages as there is increase in urbanization and westernization with changing lifestyle trends and dietary-habits. ${ }^{10}$

\section{Method}

The self structured questionnaire was prepared and was shared with female students via email and SMS through personalized links. Data was collected by using convenience sampling technique and by using descriptive statics. 


\section{Study Design}

A survey was conducted online using Google form software. The study was designed with the purpose of assessing the awareness and knowledge about breast cancer and breast self examination.

\section{Results}

Table 1- Demographics

\begin{tabular}{|l|c|c|}
\hline Variable & $\begin{array}{c}\text { Number (n) } \\
\mathbf{n = 1 2 7}\end{array}$ & Percentage \\
\hline Age & 73 & \\
$18-20$ & 46 & $63.5 \%$ \\
$21-23$ & 8 & $30.2 \%$ \\
$24-26$ & 44 & $6.3 \%$ \\
\hline Course & 49 & $34.6 \%$ \\
Medical & 33 & $38.6 \%$ \\
Non-medical & & $26 \%$ \\
Arts & 14 & $11 \%$ \\
\hline Educational qualification & 89 & $70.1 \%$ \\
Diploma & 24 & $18.9 \%$ \\
Graduate & & \\
Post graduate & 89 & $70.1 \%$ \\
\hline Resistance & 38 & $29.9 \%$ \\
Urban & & \\
Rural & & \\
\hline
\end{tabular}

127 responses were collected from participants, out of them $63.5 \%(n=73)$ lies under the age group of $18-21,30.2 \% \quad(n=46)$ under $21-21$ and $6.3 \%$ $(\mathrm{n}=8)$ under $24-26$ age group. Most participants were non medical students $38.6 \%$ followed by medical students $34.6 \%$. $70.1 \%$ students belong from urban area and $29.9 \%$ belongs from rural area.

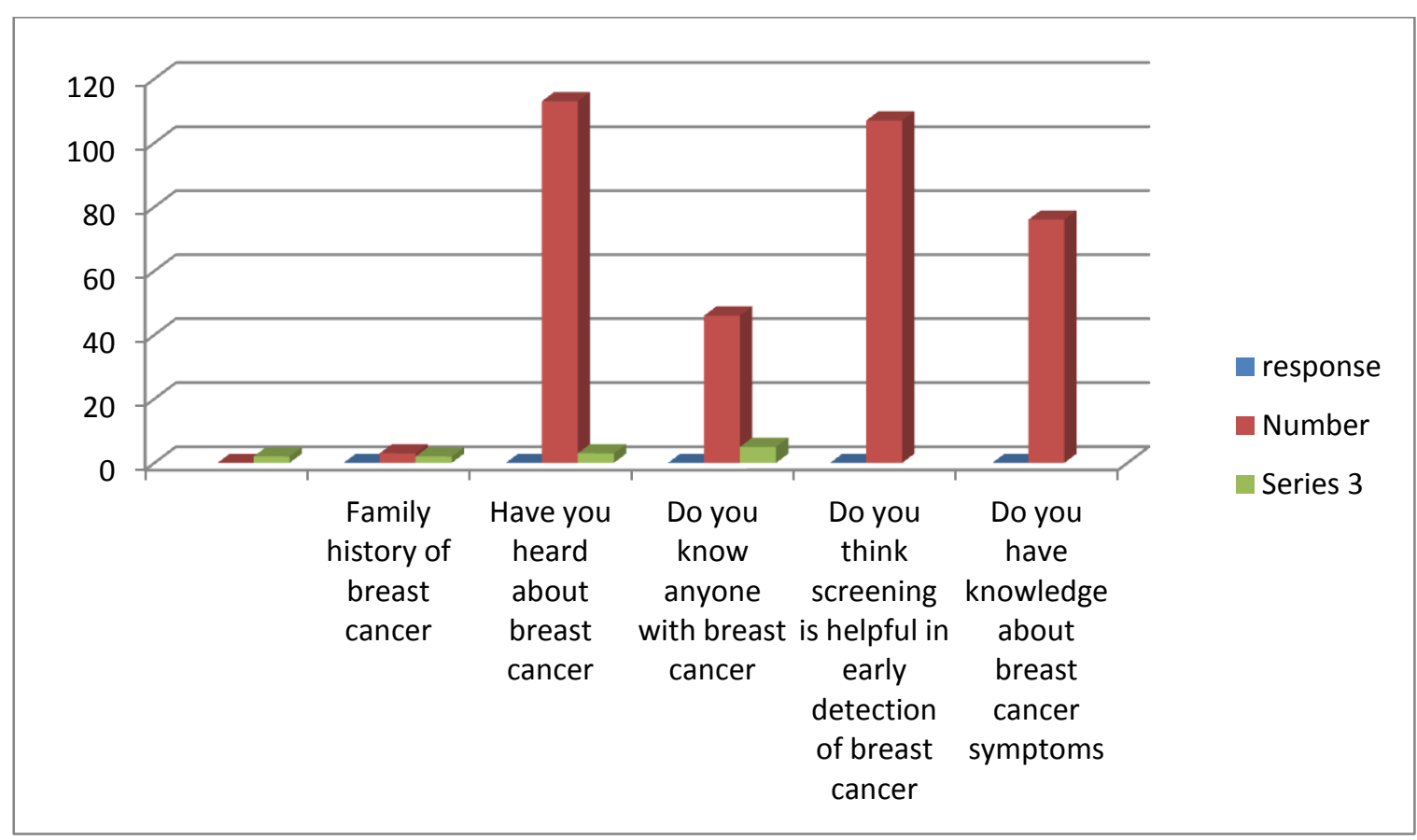

Figure 1 shows that out of 127 participants, only 113 has heard about breast cancer, 81 don't know anyone with breast cancer and 107 think screening helpful in early detection of breast cancer.

The most common source of information about breast cancer was media. 


\section{DO YOU KNOW HOW TO PERFORM BSE?}

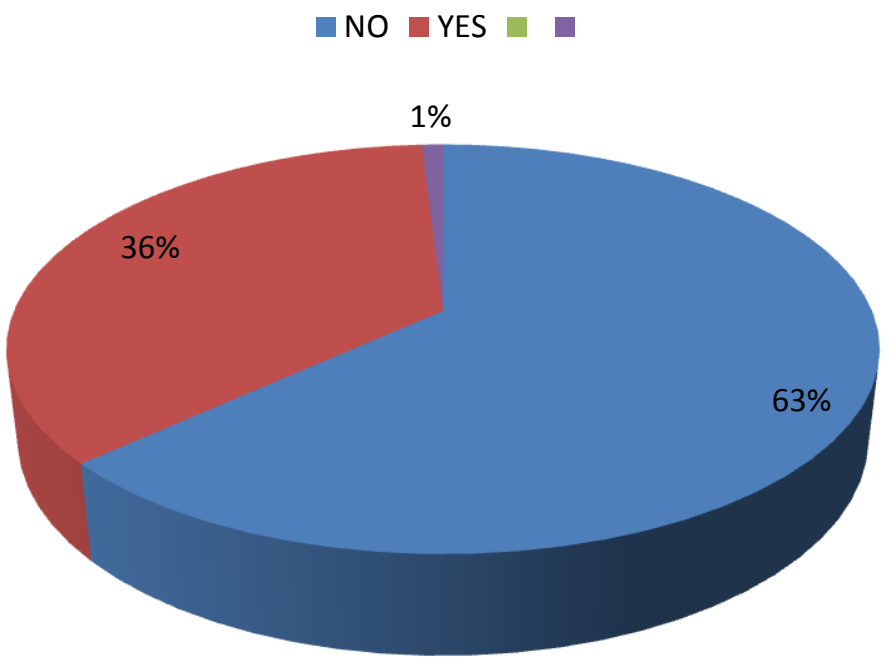

Figure 2 shows that only $36 \%$ of participants knows how to perform BSE.

Most of the participants were taught by friend to perform BSE. $41.7 \%$ participants have heard about mammography.
Out of 127 students, 90 students wanted us to share knowledge about breast cancer with them so at the end of our survey we delivered an online presentation in which we gave them a lecture about how to perform BSE properly.

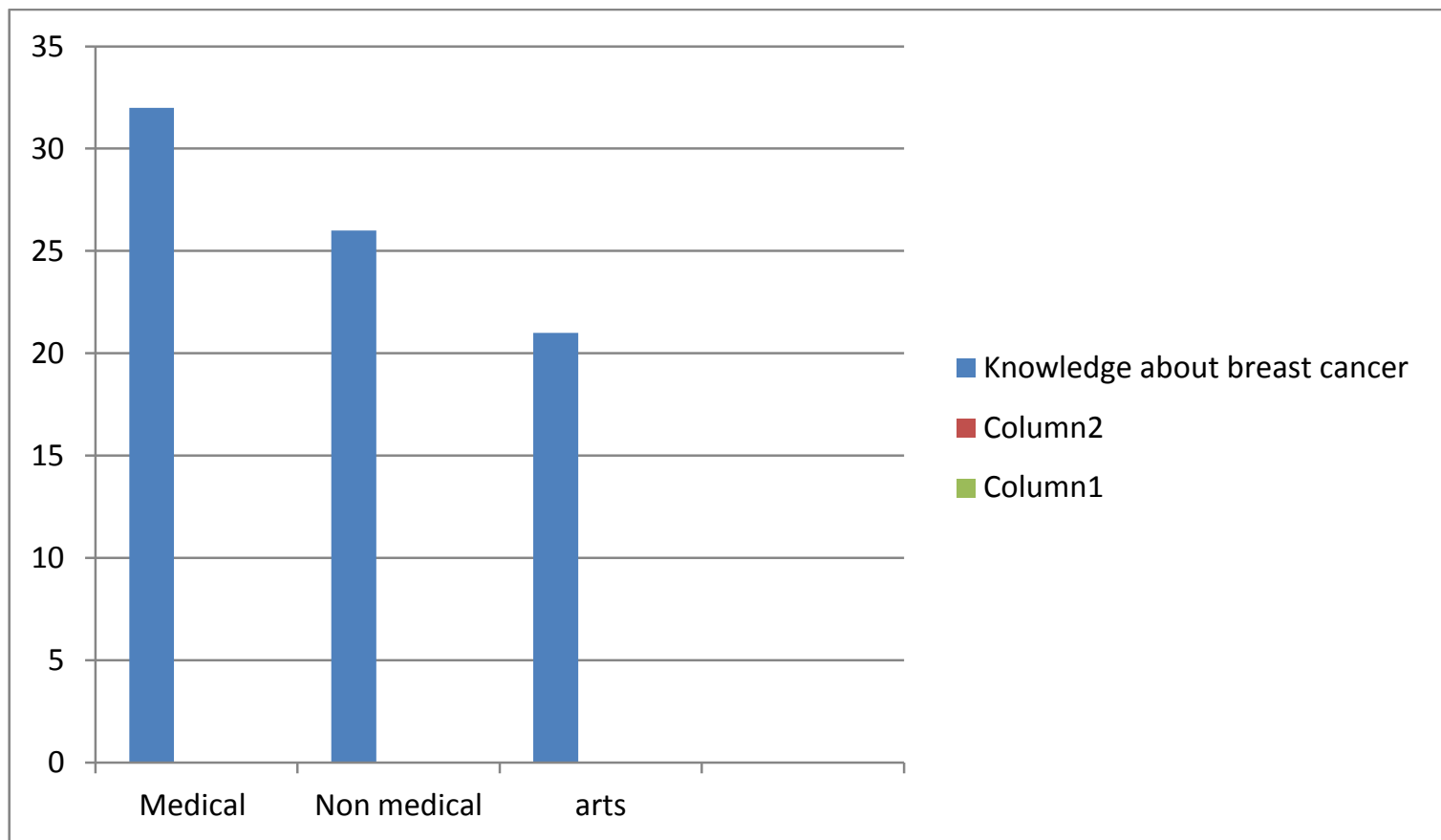

Figure 3, students from medical course were found to have more knowledge about breast cancer.

Also it was found that the students lies in the age group of 18-21 have the highest knowledge about breast cancer, followed by 21-23 age group students. 


\section{Discussion}

The overall knowledge of BSE in this population was rather very poor. The incidence of breast cancer is much less in developing countries in contrast to developed countries but the mortality rate is high due to late presentation. The cure rate in patients with disease in early stage can between 84-98\% where as in cases with metastasis, this rate falls to as low as 24 . The factors that might contribute to the late presentation of breast cancer in Indian female population include lack of knowledge and awareness about cancer screening; Breast Self-examination (BSE), and clinical breast examination. Women's knowledge and awareness about breast cancer may contribute significantly to medical help seeking behaviors and knowledge deficiency may lead to delayed presentation with advanced stages when little or no benefit is derived from any form of therapy. The hindrances in seeking access to screening and early detection included wrong health practices, social barriers, fear, social stigma associated with the disease, lack of knowledge, and level of education. Various studies have been conducted in India amongst general population for the assessment of knowledge about breast cancer and screening with methods.

\section{Limitations}

Sample size was only 127, although we shared it with 400 students but we didn't get the enough response from participants.

\section{Online Presentation}

Early detection of breast cancer is very important as it has favorable outcome. An online presentation was delivered to all the participants to aware them about breast cancer and to share knowledge of how to perform breast cancer. National breast cancer awareness programs should be launched and there should be proper utilization of media and educational channels. More awareness strategies need to be applied in order to raise the knowledge about BSE,
MAMMOGRAPHY and BREAST CANCER among people.

\section{References}

1. https://www.cancer.org/cancer/breastcancer/about/what-is-breast-cancer.html

2. https://www.cancer.gov/types/breast

3. https://www.medicalnewstoday.com/articl es/37136

4. https://www.ncbi.nih.gov/pmc/article/PM C6800411/\#_ffn_sectitle

5. Comparison of knowledge and practices of breast self examination (BSE): a pilot study in Turkey. Taşçı A, Usta YY, Asian Pac J Cancer Prev. 2010; 11(5):1417-20.

6. https://my.clevelandclinic.org/health/diagn ostics/3990-breast-self-exam

7. Humphrey LL, Helfand M, Chan BK, Woolf SH. Breast cancer screening: A summary of the evidence for the U.S. Preventive Services Task Force. Ann Intern Med. 2002;137:347-60.

8. Sun YS, Zhao Z, Yang ZN, Xu F, Lu HJ, Zhu ZY, Shi W, Jiang J, Yao PP, Zhu HP. Riskfactors and preventions of breast cancer. International journal of biological sciences. 2017;13(11):1387. Int J Biol Sci. 2017 Nov 1;13(11):1387-97.

9. Agrawal A, Tripathi P, Sahu A, Daftary J. Breast screening revisited. J Family Med Prim Care. 2014 Oct;3(4):340.

10. Malvia S, Bagadi SA, Dubey US, Saxena S. Epidemiology of breast cancer in Indian women. Asia- Pacific J Clin Oncol 2017 Aug;13(4):289-95. 13. 